\title{
How to Make Educational Lemonade Out of a Didactic Lemon: The Benefits of Listening to Your Students
}

\author{
Michael Hortsch (D) 1,2 \\ ${ }^{1}$ Department of Cell and Developmental Biology, University of Michigan Medical School, Ann Arbor, Michigan \\ ${ }^{2}$ Department of Learning Health Sciences, University of Michigan Medical School, Ann Arbor, Michigan
}

\begin{abstract}
When educators develop and introduce new learning approaches or resources, they usually have specific didactic goals in mind that they want to achieve. However, these goals may not always match the needs of their students, who often confound such plans by finding new and different uses for the educational tools that are offered to them. Originating from the author's work as the histology component director at the University of Michigan, the experience described here provides an example of a learning resource being reappropriated by the learning community. In order to encourage dental students to study histological micrographs after faculty-guided laboratory sessions were eliminated, the author prepared and offered them a series of PowerPoint files with histology images and some corresponding questions. However, instead of increasing their motivation to use the online virtual microscopy resources, students adapted this new tool for reviewing the material and for self-evaluation whether they were prepared for upcoming examinations. Although the product did not succeed as originally devised, it turned into a very popular review resource for the author's students. Students' feedback and critical input, as well as their active participation in producing additional, similar learning tools were the deciding factors for this successful change of purpose and the further development and refinement of this new learning resource. Anat Sci Educ 12: 572-576. @ 2019 American Association of Anatomists.
\end{abstract}

Key words: histology education; medical education; course evaluation; e-learning; self-assessment; student feedback; learning resources

\section{INTRODUCTION}

Histology, or microanatomy, is one of the basic science subjects of most medical and dental curricula. Histology addresses the structure and function of cells and tissues at the microscopic level and provides a foundation for many other basic sciences and clinical topics that are taught in parallel or later on to biomedical professional students. Traditionally, histology education consists of both an instructional (usually lecture-type) and a laboratory component. The histology laboratory segment helps students to develop and hone their recognition and interpretation skills of microscopic images and to link the structural

Correspondence to: Dr. Michael Hortsch; Department of Cell and Developmental Biology, University of Michigan Medical School, 109 Zina Pitcher Place, Ann Arbor, MI 48109, USA. E-mail: hortsch@umich. edu

Received 27 July 2018; Revised 19 December 2018; Accepted 15 January 2019.

Published online 5 February 2019 in Wiley Online Library (wileyonlinelibrary.com). DOI 10.1002/ase.1861

(C) 2019 American Association of Anatomists arrangement of cells and tissues to their biological function. However, recent curricular developments have resulted in less time being available for histology laboratory instruction (Drake et al., 2009, 2014), sometimes triggering the development of novel electronic self-learning tools (Khalil et al., 2010; Trelease, 2016).

Over the last 20 years, the in-classroom time for the teaching of the anatomical sciences, specifically microanatomy/ histology, has been dramatically reduced at the University of Michigan. From an independent, separate course structure with lectures and laboratory sessions, histology is now being taught in integrated, organ-based sequences at both the University of Michigan dental and medical school. As a result, faculty-guided laboratory sessions were abolished at both schools and the study of histological images was shifted to a website with virtual micrographs which require students to acquire knowledge and skills in a self-teaching modus (UMMS, 2018). Histologyteaching faculty have supplemented this change of teaching paradigm by developing additional self-learning resources (described in Holaday et al., 2013).

When about 10 years ago instructor-guided histology laboratory sessions were eliminated for dental students at the University of Michigan, the author tried to devise a way to 
encourage students to view and examine more histological images than were provided in his lecture handouts. It was hoped that this encouragement would motivate students to use the online Michigan Histology website (UMMS, 2018) that substituted for faculty-guided laboratory sessions. As a solution, the author created short PowerPoint files for his histology lecture topics that contained representative and high-quality images for students to use for an additional look at cells and tissues after lectures, thus coining the term SecondLook ${ }^{\mathrm{TM}}$ for this new educational tool (Hortsch, 2016). Adding guiding questions to these images was no more than an afterthought, mainly to entice students to use the new resource and to confront them with the challenges of histological image analysis and structure recognition. Initially, these PowerPoint files were offered to dental students and later also to medical students, who still had instructor-guided histology laboratory sessions at that time. Both groups of students quickly made this new resource their favorite supplemental histology learning tool (Holaday et al., 2013; Johnson et al., 2015), although in a different way than originally intended by the author. This development was mainly student-driven by giving feedback to the author. The importance of student feedback as a positive force for the improvement of the learning environment and resources has been recognized by others (Harvey, 2003; Richardson, 2005; Davis et al., 2014). However, it has not been widely discussed and analyzed, specifically in the anatomical sciences (Davis et al., 2014).

\section{REAPPROPRIATING THE RESOURCE}

Instead of viewing the PowerPoint files that were provided to them as an encouragement to study histological images on the Michigan Histology laboratory website (UMMS, 2018), many students used them as a quick review of the histology material taught in the corresponding lectures and the laboratory website. Some students even commented that with having these review PowerPoint files available, they skipped looking at virtual histology slides on the Michigan Histology website. This indicated the opposite outcome than was hoped for.
The questions in the SecondLook ${ }^{\mathrm{TM}}$ review tools have an open-ended format, instead of the multiple-choice-type problems that are used for histology quizzes and examinations at the University of Michigan. As the new resource does not simply provide more potential examination-type questions, something students are usually clamoring for, the use of the new PowerPoint resource as a review tool for upcoming examinations was somewhat surprising to the author.

Based on the students' feedback, the author realized that this type of didactic resource could serve as a powerful tool for students to uncover their deficiencies and gaps in knowledge and recognition skills before upcoming examinations. The SecondLook ${ }^{\mathrm{TM}}$ question structure of using the answer to a question for asking a follow-up question and so on provides a simple scheme of guiding the students' thought process and of linking seemingly distinct facts and observations into a coherent network (Hortsch, 2016) (Figure 1). Learners can see connections and better remember otherwise dissociated details, thereby resulting in a deeper and more complex understanding of the material. Based on the Socratic method, this approach is equally valid for both the basic sciences and clinical fields and is a fundamental principle of evidence-based medicine (Duban et al., 1982; Overholser, 1993; Rosenberg and Donald, 1995).

\section{FURTHER DEVELOPMENTS AND NEW LEARNING OPPORTUNITIES}

In end-of-course teaching assessments, students soon asked for more review files covering all histology lecture topics. This indicated to the author that they placed a high value on the new didactic tool. Having realized how this new resource was primarily used by students, the author completed a full series of PowerPoint files, covering all topics taught in the various histology courses at the University of Michigan. Subsequently, these original PowerPoint files were converted into a mobile application that students could use on their smartphones and computer tablets (Hortsch, 2016). The mobile application format added additional user features not available with the PowerPoint files, like adding the ability to randomize
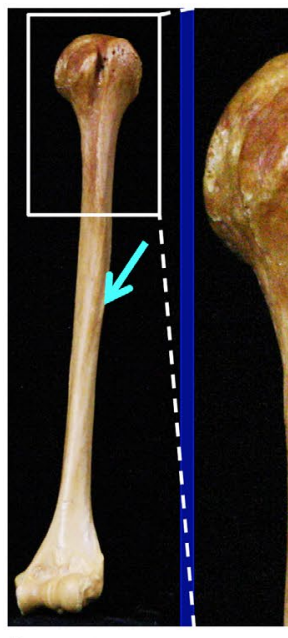

Left anterior view

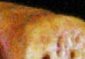

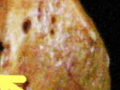
.

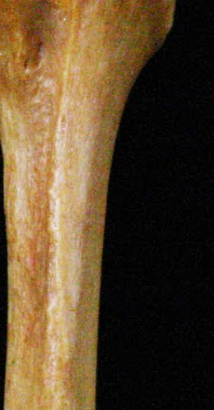

A
Name the marked grooves.

Intertubercular (bicipita) Radial sulcus (spiral) Which tendon follows the intertubercular groove?

The long head tendon of the biceps brachii muscle

Which nerve travels in the spiral groove and is in danger of injury by a midhumeral fracture? The radial nerve

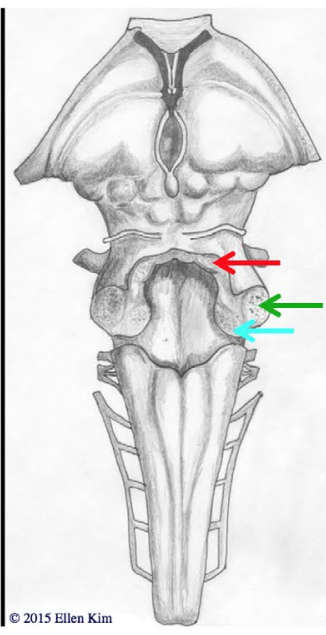

What three large fiber tracts attach the cerebellum to the brain stem?

The superior, middle and inferior cerebellar peduncles

Locate the three cerebellar peduncles in the image.

What types of fibers travel in each of the cerebellar peduncles?

Mainly

efferent fibers from deep cerebellar nuclei

to the diencephalon and the brain stem

Middle cerebellar peduncle:

Mainly afferent pontine fibers

Inferior cerebellar peduncle: Mainly afferent fibers from the spinal cord and the medulla oblongata, reciprocal connections with vestibular structures

\section{Figure 1.}

Sample pages from the SecondLook ${ }^{\mathrm{TM}}$ educational tool. A, Musculoskeletal Anatomy series and B, Neuroanatomy series. Both panels are shown with all the questions and answers revealed. 
the order of the content pages and to combine different topics into personalized review sessions. More recently, a third SecondLook ${ }^{\mathrm{TM}}$ format, a website version, has been added for students using laptop and desktop computers that will not run the mobile app. These additional, user-friendly features and different access formats made the new resource even more valuable as a review tool.

Listening to one's students has its rewards. The SecondLook ${ }^{\mathrm{TM}}$ review resource is now the most popular supplemental study resource for students learning histology at the University of Michigan. When surveyed about their use of histology learning tools, 95 to $97 \%$ of histology learners said that they "always" or "frequently" use it, usually in preparation for upcoming histology quizzes and examinations (Holaday et al., 2013; Johnson et al., 2015). Most students use the SecondLook ${ }^{\mathrm{TM}}$ resources multiple times while learning histology (on average about three times) with the highest use about one day before an upcoming quiz or examination. Many medical and dental students mentioned to the author that they reused the SecondLook ${ }^{\mathrm{TM}}$ tools during their preparations for professional board examinations such as the United States Medical Licensing Examination ${ }^{\circledR}\left(\right.$ USMLE $\left.^{\circledR}\right)$ and the National Board Dental Examination (NBDE) Part I).

Both official teaching evaluations, as well as personal interactions with individual students made the author realize that students' need for efficient review resources in an ever more complex and demanding learning environment is not only important, but also universal. This insight opened a second avenue of learning, both for the author and his students. The basic concept of the SecondLook ${ }^{\mathrm{TM}}$ self-assessment tool is easily transferable to other subjects, especially those involving images, like the other anatomical sciences (Figure 1). Therefore, it was not surprising that a number of more senior students, having experienced the value of the new resource during their histology education, approached the author and suggested the creation of additional resources for their junior peers. Several new self-assessment tools have now been produced by upper class dental and medical students with the help and under the guidance of faculty content experts (Figure 1). The participating students often start the project to fulfill a non-classroom research or education requirement in their curriculum and sometimes have the intention of specializing in or of pursuing residency training in these fields. In addition, the new projects have expanded the concept into clinical areas for which few efficient review tools are currently available.

Thus, originally designed as an enticement to study histological images, the SecondLook ${ }^{\mathrm{TM}}$ idea has evolved into a general self-assessment tool that allows students to quickly and efficiently review their knowledge of a basic science or clinical subject and later be the creators of new, advanced educational material for their junior peers.

Students' input was the guiding principle in this evolution, reflecting the shared responsibility of the teacher and the learner in a competency-based education framework for the development of lifelong learning and self-assessment skills (Schumacher et al., 2013). It is hoped that the simplicity of the didactic approach and the requirement of only limited PowerPoint mastery will enable educators at other schools to create similar resources for and also with their own students, covering other basic science and clinical subjects. The translation into a mobile app or interactive website format is entirely optional and many University of Michigan students still prefer to use the original PowerPoint files on their laptop computers.

\section{THE IMPORTANCE OF STUDENT- TEACHER COMMUNICATION}

For some time, the importance of student feedback for the improvement of learning materials, didactic strategies, and the educator's effectiveness has been recognized (Tyler, 1949; Cohen, 1980; Nathenson and Henderson, 1980; Harvey, 2003; Davis et al., 2014). In addition, it can also support other didactic goals, such as the promotion of students' professionalism (Camp et al., 2010; Youdas et al., 2013).

There are multiple pathways by which educators receive student feedback about their teaching, as well as for the offered didactic resources and the learning environment, each with specific advantages and disadvantages (Richardson, 2005; Yao and Grady, 2005; Fluckiger et al., 2010). Thus, there are a number of ways for educators to learn how the didactic resources that they offer to their students are being regarded and used (or not used). Both teaching evaluations and personal interactions with students alerted the author that they valued his new learning resource.

First, educators usually receive standard teaching evaluations after the completion of a course. Although not specifically prompted, students often mentioned the SecondLook ${ }^{\mathrm{TM}}$ resource in their histology teaching evaluations and described it as particularly helpful. In general, official course evaluations remain the most common way to receive students' critiques and comments. A second, very useful avenue of communication is to take a few minutes and to talk with individual or small groups of students, for example after class time, when advising students, or at other opportunities outside the classroom. In the author's experience, professional students are usually happy to give candid feedback.

However, such feedback is of little values unless educators take responsibility to consider and to act upon it (Richardson, 2005; Moore and Kuol, 2005). The role of a good teacher is more complex than just being an expert in a specific field. It includes diverse aspects, like being a role model, facilitator, assessor, and resource developer (Harden and Crosby, 2000). An effective educator will try not only to provide constructive feedback to his/her students, but also to receive it (Harden and Crosby, 2000; Korthagen et al., 2014). To be successful, this process has to be based on effective interpersonal relationships (Frymier and Houser, 2000). A bidirectional, efficient teacher-student communication involving learners as active partners is often of central importance for the success of a new didactic strategy or concept (Boud and Molloy, 2013; Korthagen et al., 2014; Border, 2017). In order to be honest and true, such communication must also be built on mutual trust and respect (Syverud, 1993).

In this context, it should be noted that new technologies like social media also offer new opportunities to engage with students in an effective and fruitful exchange of ideas and information. That platforms, like Facebook and Twitter, when well-integrated into a course, can raise students' engagement has already been demonstrated (Junco et al., 2011; Cheston et al., 2013; Hennessy et al., 2016). Their value to enhance knowledge acquisition and to serve as conduits for valuable and actionable feedback and student-teacher collaborations still needs additional research and more rigorous testing (El Bialy and Jalali, 2015). 


\section{CONCLUSIONS AND CAUTIONS}

The author's experience described here serves as an example of role reversal: the educator becoming the learner and the students becoming teachers. In today's learner-centered educational environment, instructors need to recognize the needs of their students and identify didactic approaches and resources that will help them reach the intended learning outcomes (Spencer and Jordan, 1999). However, the best didactic intentions and careful plans sometimes go awry. It is at these moments that educators have a chance to step back, reevaluate, and to change course. This process requires careful observation of students' behaviors, a recognition of their needs, and a detailed understanding of the reasons why students make specific choices during the learning process. Flexibility of personal teaching strategies and an ability to reexamine cherished didactic approaches are also demanded of the teacher.

Students often find novel and non-intended applications for the educational material and the resources that are prepared for and offered to them. However, these usages may not always support a positive or improved learning outcome (Hortsch, 2015). A few of the University of Michigan histology students responded that having the SecondLook ${ }^{\mathrm{TM}}$ resource available, they did not use the Michigan Histology website and did not participate in other learning opportunities, like lectures. The e-learning community appears to agree that electronic learning tools work best as part of a network of complementary learning resources, including traditional educational strategies (Alexander, 2001; Childs et al, 2005; Ruiz et al., 2006).

The successful example of teacher-student interaction reported in this article should not be misread that students are always correct and are the best judges of didactic strategies and educational resources (Scott, 1999; James, 2001). After all, they are still learners and usually lack the extended experience and subject knowledge of their educators. However, they can give educators valuable feedback, when to change and which of their didactic concepts and offerings is working or not. In addition, teachers' and students' objectives and motivations are not always compatible and may sometimes conflict (Border, 2017). However, the author's experience described here indicates that sometimes they harmonize and complement each other.

Another limiting factor can be the effectivity or ineffectiveness of the feedback provided or received. As Hattie and Timperley noted in their 2007 paper, "Feedback has no effect in a vacuum; to be powerful in its effect, there must be a learning context to which feedback is addressed" (Hattie and Timperley, 2007). In her 1993 paper, Kathleen Brinko outlined several important aspects that influence the effectiveness of feedback for the improvement of teaching (Brinko, 1993): the first being the source of the feedback, followed by what is being delivered and when. Hattie and Timperley (2007) added three additional major factors that can turn feedback ineffective: the balance between positive and negative feedback, the classroom use of feedback, and the role of assessment in feedback. Therefore, educators must be aware how they provide feedback to their students and whether it is correctly received and understood (Orsmond and Merry, 2011) and also realize when students provide feedback back to them and what that feedback means.

It is always important to listen to one's students, not only to learn which educational resources they prefer and why, but also how they use them. Success in education is often grounded in being adaptable to students' needs and preferences without following them blindly (Davis et al., 2014). However, an emphasis on the mutual goals of the educator and the students is beneficial to this process.

\section{ACKNOWLEDGEMENT}

The author would like to thank Dr. Wojciech Pawlina and the anonymous reviewer, as well as Dr. Sarah Becker-Hortsch for their helpful input, which was extremely helpful for improving the original manuscript.

\section{NOTE ON CONTRIBUTOR}

MICHAEL HORTSCH, Ph.D., is a professor in the Departments of Cell and Developmental Biology and of Learning Health Sciences at the University of Michigan Medical School in Ann Arbor, Michigan. Since 1991, he has taught medical and dental histology at the University of Michigan. He is interested in the development of electronic educational tools and his research addresses how these resources impact students' learning.

\section{LITERATURE CITED}

Alexander S. 2001. E-learning developments and experiences. Educ + Train 43:240-248.

Border S. 2017. Working with students as partners in anatomy education. Anat Sci Educ 10:613-614.

Boud D, Molloy E. 2013. Rethinking models of feedback for learning: The challenge of design. Assess Eval High Educ 38:698-712.

Brinko KT. 1993. The practice of giving feedback to improve teaching. What is effective? J High Educ 64:574-593.

Camp CL, Gregory JK, Lachman N, Chen LP, Juskewitch JE, Pawlina W. 2010. Comparative efficacy of group and individual feedback in gross anatomy for promoting medical student professionalism. Anat Sci Educ 3:64-72.

Cheston CC, Flickinger TE, Chisolm MS. 2013. Social media use in medical education: A systematic review. Acad Med 88:893-901.

Childs S, Blenkinsopp E, Hall A, Walton G. 2005. Effective e-learning for health professionals and students-Barriers and their solutions. A systematic review of the literature-Findings from the HeXL project. Health Info Libr J 22:20-32.

Cohen PA. 1980. Effectiveness of student-rating feedback for improving college instruction: A meta-analysis of findings. Res High Educ 13:321-341.

Davis CR, Bates AS, Ellis H, Roberts AM. 2014. Human Anatomy: Let the students tell us how to teach. Anat Sci Educ 7:262-272.

Drake RL, McBride JM, Lachman N, Pawlina W. 2009. Medical education in the anatomical sciences: The winds of change continue to blow. Anat Sci Educ 2:253-259.

Drake RL, McBride JM, Pawlina W. 2014. An update on the status of anatomical sciences education in United States medical schools. Anat Sci Educ 7:321-325.

Duban S, Mennin S, Waterman R, Lucero S, Stubbs A, Vanderwagen C, Kaufman A. 1982. Teaching clinical skills to pre-clinical medical-students - Integration with basic science learning. Med Educ 16:183-187.

El Bialy S, Jalali A. 2015. Go where the students are: A comparison of the use of social networking sites between medical students and medical educators. JMIR Med Educ 11:e7.

Fluckiger J, Vigil YT, Pasco R, Danielson K. 2010. Formative feedback: Involving students as partners in assessment to enhance learning. Coll Teach 58:136-140.

Frymier AB, Houser ML. 2000. The teacher-student relationship as an interpersonal relationship. Comm Educ 49:207-219.

Harden RM, Crosby J. 2000. AMEE Guide No 20: The good teacher is more than a lecturer-The twelve roles of the teacher. Med Teach 22:334-347.

Harvey L. 2003. Student feedback. Qual High Educ 9:3-20.

Hattie J, Timperley H. 2007. The power of feedback. Rev Educ Res 77:81-11.

Hennessy CM, Kirkpatrick E, Smith CF, Border S. 2016. Social media and anatomy education: Using Twitter to enhance the student learning experience in anatomy. Anat Sci Educ 9:505-515.

Holaday L, Selvig D, Purkiss J, Hortsch M. 2013. Preference of interactive electronic versus traditional learning resources by University of Michigan medical students during the first year histology component. Med Sci Educ 23:607-619. 
Hortsch M. 2015. "How we learn may not always be good for us" - Do new electronic teaching approaches always result in better learning outcomes? Med Teach 37:507-509.

Hortsch M. 2016. Taking a SecondLook ${ }^{\mathrm{TM}}$ at a time-efficient self-review resource. Med Sci Educ 26:3-4.

James D. 2001. Why students can't be customers in the classroom. Coll Univ $77: 45-46$.

Johnson S, Purkiss J, Holaday L, Selvig D, Hortsch M. 2015. Learning histology Dental and medical students' study strategies. Eur J Dent Educ 19:65-73.

Junco R, Heiberger G, Loken E. 2011. The effect of Twitter on college student engagement and grades. J Comput Assist Lear 27:103-189.

Khalil MK, Nelson LD, Kibble JD. 2010. The use of self-learning modules to facilitate learning of basic science concepts in an integrated medical curriculum. Anat Sci Educ 3:219-226.

Korthagen FAJ, Attema-Noordewier S, Zwart RC. 2014. Teacher-student contact: Exploring a basic but complicated concept. Teach Teach Educ 40:22-32.

Moore S, Kuol N. 2005. Students evaluating teachers: Exploring the importance of faculty reaction to feedback on teaching. Teach High Educ 10:57-73.

Nathenson MB, Henderson ES. 1980. Using Student Feedback to Improve Learning Materials. 1st Ed. London, UK: Croom Helm Ltd. 208 p.

Orsmond P, Merry S. 2011. Feedback alignment: Effective and ineffective links between tutors' and students' understanding of coursework feedback. Assess Eval High Educ 36:125-136.

Overholser JC. 1993. Elements of the Socratic method: 1. Systematic questioning. Psychother 30:67-74.

Richardson JT. 2005. Instruments for obtaining student feedback: A review of the literature. Assess Eval High Edu 30:387-415.
Rosenberg W, Donald A. 1995. Evidence based medicine - An approach to clinical problem-solving. BMJ 310:1122-1126.

Ruiz JG, Mintzer MJ, Leipzig RM. 2006. The impact of e-learning in medical education. Acad Med 81:207-212.

Schumacher DJ, Englander R, Carraccio C. 2013. Developing the master learner: Applying learning theory to the learner, the teacher, and the learning environment. Acad Med 88:1635-1645.

Scott SV. 1999. The academic as service provider: Is the customer 'always right? J High Educ Pol Manag 21:193-202.

Spencer JA, Jordan RK. 1999. Learner centred approaches in medical education. BMJ 318:1280-1283.

Syverud KD. 1993. Taking students seriously: A guide for new law teachers. J Legal Educ 43:247-259.

Trelease RB. 2016. From chalkboard, slides, and paper to e-learning: How computing technologies have transformed anatomical sciences education. Anat Sci Educ 9:585-602.

Tyler RW. 1949. Basic Principles of Curriculum and Instruction. 1st Ed. Chicago, IL: The University of Chicago Press, Ltd. 144 p.

UMMS. 2018. University of Michigan Medical School. Michigan Histology and Virtual Microscopy Learning Resources. University of Michigan Medical School, Ann Arbor, MI. URL: http://histology.sites.uofmhosting.net [accessed 15 December 2018].

Yao Y, Grady ML. 2005. How do faculty make formative use of student evaluation feedback?: A multiple case study. J Pers Eval Educ 18:107-126.

Youdas JW, Krause DA, Hellyer NJ, Rindflesch AB, Hollman JH. 2013. Use of individual feedback during human gross anatomy course for enhancing professional behaviors in doctor of physical therapy students. Anat Sci Educ 6:324-331. 